\title{
El Niño Dios va al fútbol: vestir una imagen religiosa al servicio de la nación mexicana
}

\section{The Holy Infant Goes to the Football: How a Religious Statue is Dressed to Serve the Mexican Nation}

\author{
Miguel Lisbona Guillén ${ }^{1}$ \\ Universidad Nacional Autónoma de México \\ Miguel A. Rivera ${ }^{2}$ \\ Universidad Nacional Autónoma de México
}

\section{RESUMEN}

El Niño de Atocha, imagen ubicada en una iglesia de la Ciudad de México, es transformado durante ciertos partidos de la selección mexicana de fútbol en el seguidor número 12 al ser vestido como jugador. Así resulta concebido, por los creyentes que participan de su transformación, de manera divergente a la deseada representación pregonada por la Iglesia católica para las imágenes religiosas, más bien se convierte en una real encarnación metonímica de los incondicionales del seleccionado; condensación temporal de la nación vívida mediante el uso de la imaginería religiosa.

Palabras clave: Fútbol; Nación; Religiosidad; Imaginería.

\section{SUMMARY}

El Niño de Atocha (or Holy Infant of Atocha) is a statue in a church in Mexico City that is dressed up and turned into the Mexican national football team's twelfth player for certain matches. This practice, which diverges from the desired representation advocated by the Catholic Church, makes the figure a metonymic incarnation for unconditional fans, using religious imagery to temporarily encapsulate national sentiment.

Keywords: Football; Nation; Religiosity; Imagery.

\section{INTRODUCCIÓN}

El fútbol, como parte de esa vida que tenemos, me sirve entonces como una puerta de entrada a esos mundos íntimos en los que se juegan asuntos mucho más definitivos. Un escenario, o un telón de fondo, de las cosas esenciales que señalan y definen todas las vidas (Sacheri 2014: 10).

En México hablar de la relación entre imaginería religiosa y nación no resulta

\footnotetext{
${ }^{1}$ Correo electrónico: mlisbonag@hotmail.com. ORCID iD: <https://orcid.org/0000-0002-5700-741X>.

${ }^{2}$ Correo electrónico: mriver@servidor.unam.mx. ORCID iD: <https://orcid.org/0000-0002-5911-8455>.
} 
novedad en las ciencias sociales. Desde los estudios históricos, hasta los sociológicos y antropológicos, se ha hecho hincapié en la relevancia que para conformar el nuevo Estado nacional juega la Virgen de Guadalupe. Trabajos clásicos como los de Jacques Lafaye (2002) o David Brading (2002) así lo confirman. Igualmente, pero de más reciente factura, existe la preocupación por las versiones populares de construcción o visión de la nación (Héau y Giménez 2005), o por cómo el sentimiento nacional de los mexicanos se establece, y no necesariamente de manera separada, con sistemas rituales de distinta procedencia y que involucran a lo religioso, a través del catolicismo guadalupano, y lo civil gracias a los ritos y símbolos creados tras la Revolución mexicana (Torre 2006 y 2014). Análisis confluyentes, con distintos matices, para apreciar una especie de polifonía nacionalista que cuenta con hilos conductores nítidos, a través de los símbolos patrios, pero que se desparrama en el accionar de los mexicanos.

El presente artículo desea destacar, en la misma línea apuntada en el párrafo anterior, los nexos entre lo religioso y lo nacional, aunque en este caso sean mediados por una imagen no guadalupana y el fútbol se convierta en la guía para desplegar la representación de lo patrio. El respaldo a la selección mexicana de fútbol se incorpora al culto religioso de una imagen católica, el Niño de Atocha, ubicada en un histórico recinto sagrado de Ciudad de México. Esa circunstancia exhibe la convivencia de un deporte reglamentado y espectacularizado a nivel mundial, el fútbol, y la transgresión que representa el uso de una imagen católica para vestirla de seleccionado mexicano, con la finalidad de influir en el resultado deportivo. En las siguientes páginas, y para explicarlo, se intercala la revisión crítica de bibliografía y documentación institucional, con datos etnográficos de campo y entrevistas. Cabe destacar que como la selección mexicana no ha competido en Mundiales cuando se efectuaron las entrevistas, que es cuando la actividad de vestir al Niño Dios se convierte en observable, el trabajo de campo no pudo contar con la visión directa de tal hecho. Sin embargo, se consideró pertinente poner sobre la mesa de discusión elementos que conjugan el fútbol espectáculo, la representación de la nación y la religiosidad, y todo ello a través de la imaginería católica empleada para reforzar una versión del nacionalismo imaginado por mexicanos sin responsabilidades políticas. Forma de anticipar siguientes trabajos de investigación y etnografías.

\section{FÚTBOL: RELIGIOSIDAD E IDENTIDAD NACIONAL}

La relación sugerida entre fútbol y religiosidad desde las ciencias sociales no es novedosa, pero en los últimos años la expansión de las tecnologías de la información hace posible las transmisiones deportivas en todo el orbe (Castells 2005: 56). Ello significa, incluso, que se afirme que el deporte contemporáneo "vive un momento frenético: la era de su exceso como bien informacional" (Martínez 2010: 10). Las acciones que unen práctica futbolística y manifestaciones religiosas visibles no tienen, por supuesto, un único ámbito físico para llevarse a cabo, ni involucran siempre a los mismos actores. Estas obviedades, por mínimo seguimiento que se dé al fútbol profesional, no han tenido la atención puntual de las ciencias sociales latinoamericanas (Alabarces 2000: 12), donde disciplinas e investigadores han sido reacios, hasta 
hace pocos años, a apreciar en la práctica deportiva un fenómeno de masas de indudable influencia o reflejo de la propia sociedad contemporánea, y en el caso que ocupará las siguientes páginas el desprecio puede ser doble, puesto que el uso de imágenes religiosas en ciertos ámbitos tampoco ha dejado de ser considerada una actividad supersticiosa. Algo que Eduardo Galeano definió con claridad:

En qué se parece el fútbol a Dios? En la devoción que le tienen muchos creyentes y en la desconfianza que le tienen muchos intelectuales [...]. El desprecio de muchos intelectuales conservadores se funda en la certeza de que la idolatría de la pelota es la superstición que el pueblo merece [...]. En cambio, muchos intelectuales de izquierda descalifican al fútbol porque castra a las masas y desvía su energía revolucionaria (Galeano 2015: 36).

Parece indudable que existen en los deportes de masas analogías entre las expresiones manifestadas en espacios deportivos y religiosos (Bromberger 2000: 267-271). Algo que de forma contundente, y discutible, señaló Brohm (1982) al hablar del deporte como nueva religión de las masas industriales, y sustituto profano de las antiguas religiones. Estas afirmaciones han deseado ver similitudes en las delimitaciones espaciales y reglas litúrgicas, tanto en el deporte como en las religiones monoteístas, mismas que son más visibles en territorios urbanos. También el fervor religioso ha sido equiparado con el deportivo al acompañarnos desde la infancia a la muerte, así nuestras creencias o devociones emergen entre seguidores de futbolistas o equipos deportivos. Esta afinidad descrita por el narrador Hornby (2012: 258), al aseverar que los futbolistas son nuestros representantes, aunque sean elegidos por el entrenador, es equiparable a lo sucedido con los intermediarios entre Dios y los creyentes.

Como se apuntó la investigación sobre el fútbol, desde la perspectiva social, ha crecido en América Latina, y así lo demuestran las revisiones temáticas y de corrientes teóricas efectuadas por Alabarces (2000 y 2004), Angelotti (2010), Magazine y Martínez (2009) o Villena (2003). Casi todas destacan la tendencia que como espectáculo deportivo ha tenido el balompié para condensar identidades sociales y culturales, aunque se construyan a partir de "narrativas cambiantes" (Sandoval 2013: 32). Identificaciones barriales, urbanas, regionales o nacionales aparecen en confrontaciones futbolísticas en cualquier ámbito geográfico que se estudie. Incluso existen casos en los que se sitúa al deporte como parte de la construcción histórica nacional, como observó Archetti (2001) en Argentina, siguiendo los pasos abiertos en Brasil por Da Matta (1982). La cercanía entre el juego del seleccionado nacional mexicano y la devoción religiosa la expresó a la perfección Carlos Monsiváis (1991: 31) cuando ponía en boca de un aficionado la siguiente frase que reflejaba el sentir cuando jugaba la Verde: "Son horas en que la patria nos entra por los ojos y los oídos y se nos sale por la garganta". Tal circunstancia ha sido o es alimentada por ciertos gobiernos para la "promoción nacionalista" (Villena 2003: 23), pero también es asumida por la misma ciudadanía para reconstruir formas de sociabilidad o confrontación ajenas al deseado discurso surgido de los Estados.

Un caso cercano al mexicano, el de Costa Rica, fue estudiado por Sergio Villena para exponer cómo el fútbol se convierte en "un espacio discursivo privilegiado para la elaboración de narrativas de la identidad nacional" (Villena 2010: 138); así en las competiciones internacionales eclosiona como uno de los "núcleos simbólicos en la esfera pública urdida en torno a lo que significa ser (o no ser) un/a costarricense" 
(Villena 2010: 138). Ello se enlaza con la religión católica, en un Estado confesional como el costarricense, y se demuestra a través de lo constante que son las "prácticas religiosas para convocar el favor de Dios y la Virgen con fines de obtener la victoria y el éxito deportivo para la nación [...] entre los jugadores y el cuerpo técnico de la "sele" (Villena 2010: 139). Esta unión de lo religioso y el nacionalismo crece durante la celebración de Copas Mundiales y las victorias de la selección se ven "al menos parcialmente, como resultado de un don divino, como una especie de premio [...] a la fidelidad religiosa de los costarricenses, reforzando así el sentimiento de pueblo elegido que está en la base del nacionalismo costarricense" (Villena 2010: 144).

Otro caso examinado ha sido el uruguayo, donde Bayce (2003: 174) complejiza la creación de autoimágenes y heteroimágenes, emanadas con los triunfos históricos y forma de juego uruguayo, en relación con la visión de la nación (2003: 174). A estos casos se unen otros estudios que equiparan las acciones del seleccionado nacional con la imagen del país y la identidad nacional, como se ha visto para Colombia (Vélez 2010: 214-215).

En México se ha señalado esa homologación, en forma de "narrativa épica", donde la selección nacional "une a todo un país y [...] los ciudadanos se ven reflejados en los futbolistas" (Gameros 2010: 231-232). A través del fútbol se construyen imágenes de la nación y sus ciudadanos (Fábregas 2001), representados estos últimos por los héroes futbolísticos y sus características. Por eso no ha sido una excepción comparar la celebración futbolística con el anhelo, momentáneo y ficticio, de comunidad, de nación inventada siguiendo el modelo de Anderson (1993). Es esta una forma de proporcionar metaidentidades, en el caso de las competiciones mundialistas, entendidas como identidades nacionales puestas en juego en esas justas (Antezana 2003: 9092). Un hecho que no debe extrañar si se toma en cuenta que el surgimiento del fútbol coincide con la conformación de la mayoría de Estados modernos (Tuñón y Brey 2010: 163).

También existen demostraciones de todo lo contrario, es decir, de cómo las rivalidades en el fútbol nacional forman parte del dificultoso proceso de integración regional de la nación mexicana, que se desea centralizada pero que cuenta con aristas en su conformación, tal es el caso del "desdibujamiento" de México como unidad que ha sido expresado con claridad por Fábregas (2001) y Magazine y Martínez (2009).

Esta homologación metonímica de la selección nacional con la nación, y sus miembros, es vivida, en muchas ocasiones, "Como algo trascendental" y "vincula y enlaza a sus seguidores con algo superior al "nosotros" visible y concreto" (Martínez 2010: 14). Tanto es así que en "el Mundial sí pierdes el honor nacional porque la selección de fútbol es la nación" (Kuper 2014: 335). Se trata de una muestra de un "nacionalismo banal", en palabras de Michael Billig (cit. en Sandoval 2013: 7), que ofrece, sin embargo, "formas de identificación que no corresponden con las [...] ilustradas que dieron lugar a los discursos de nación" (Sandoval 2013: 7).

A la nación sobre el pasto se añade, en estas páginas, el papel jugado por la imaginería religiosa católica para estructurar la religiosidad y, en el caso que nos ocupa, su vínculo con ciertas actividades futbolísticas que convocan y condensan el imaginario nacional. Es así que tanto desde el periodo posrevolucionario mexicano (Lisbona Guillén 2006: 63), como en la actualidad, el uso de imágenes sacras históricas, o las nuevas que se incorporan a las devociones presentes, no dejan de ser consideradas prácticas supersticiosas fuera de los espacios reconocidos por la Iglesia católica. Esta 
última confrontada, a veces de manera simulada, con el uso de la imaginería por parte de creyentes que se alejan del dogma católico. Ello es fundamental para entender lo que a continuación se expresa, que es la utilización de una imagen, conocida como el Santo Niño de los Milagros, situada en la iglesia de San Gabriel Arcángel de Tacuba, en la capital de México, para ser vestida de seleccionado mexicano y apoyar al representativo nacional cuando enfrenta retos competitivos como lo es una Copa Mundial.

\section{LO VISIBLE DE LO INVISIBLE EN EL FÚTBOL}

Cuando toqué por primera vez — tenía doce años- un verdadero balón de fútbol, me hallaba en presencia de un objeto sagrado (Dimitrijevic 2010: 21).

Tal vez el caso más referencial de la traslación del imaginario deportivo al religioso sea la creación de la Iglesia Maradoniana en Argentina, cuyo culto, relacionado con la simbología católica, cuenta con templos y una ritualidad sacramental (bautizos, matrimonios) que abarca aspectos del ritmo social de sus participantes, como son la celebración de la Navidad Maradoniana el 30 de octubre, o la Pascua el 22 de junio. De la misma manera posee un libro sagrado llamado "Yo soy el Diego de la Gente", oraciones y sitios benditos (Vidal 2012: 258). Estos elementos le permiten a Marcelo Serra (2015: 13) hablar de la eficacia simbólica de este tipo de culto, reafirmado por situaciones previas que otorgaban a un poder superior, celestial, la consecución de goles definitivos como el de la mano de Dios (2015: 21). Inclusive siguiendo el discurso del propio Maradona, quien asegura estar "tocado "por la mano de Dios"”, se aprecia su calidad de profeta (Tamburrini 2000: 23-47; Vidal 2012: 188-189) o de santo, junto a San Genaro cuando jugaba en el Nápoles (Vázquez Montalbán 2005: 37; Vidal 2012: 193). Este último hecho ratificado con el Te-Diegum "conducido por Maradona" en 1991 para conmemorar, tras cuatros años, el primer título conseguido por el equipo del sur de Italia (Vidal 2012: 193). A ello hay que agregar que en la obra teatral Tres veces 10, presentada en el emblemático teatro de la ópera de San Carlo en Nápoles, donde participó a mediados de enero de 2017, afirmó que ahora "hay dos Papas argentinos: Francisco y yo"

Sin llegar a la institucionalización de un culto, como en el caso de los seguidores del futbolista argentino, se producen constantemente manifestaciones que reportan el nexo entre fútbol y religiosidad, y solo algunos ejemplos sirven para ilustrarlo. Tras una sequía de triunfos, el equipo de las Chivas de Guadalajara (México) ganó el trofeo apertura de la Copa MX en noviembre de 2015. Finalizado el partido, el entrenador, "el pelado" Matías Almeyda, llamó a todos sus jugadores para que se reunieran arrodillados en el césped y oraran una plegaria, algo nada desconocido para ese equipo surgido en una región de raigambre católica y que cuenta con una capilla en su vestuario (Fábregas 2001). Incluso en tiempos anticlericales, coincidentes con el Mundial de fútbol de 1930, el entrenador del equipo mexicano, Juan Luqué de Serrallonga, "dirigió un mensaje de aliento a los jugadores reunidos en su hotel de Montevideo:

\footnotetext{
${ }^{3}$ Diario Época. 2017. "Maradona revive después de 30 años los recuerdos del primer título del Nápoles". Diario Época (17 ene.). Disponible en: <http://diarioepoca.com/672451/maradona-revivedespues-de-30-anos-los-recuerdos-del-primer-titulo-del-napoles/>. Fecha de consulta: 17 ene. 2017.
} 
les aseguró que la Virgen de Guadalupe estaba rezando por ellos allá en la patria, en el cerro de Tepeyac" (Galeano 2015: 75).

Estas acciones colectivas son secundadas por otras de carácter individual. Muchos futbolistas utilizan talismanes y conjuros, como los llamó Galeano (2015: 74), o se santiguan una o varias veces al tocar el césped. La forma de iniciar los partidos del mexicano "Chicharito" Hernández, las acciones del brasileño y pastor Kaká, o la muy sonada de Neymar Jr. que, tras obtener la medalla de oro en fútbol durante las Olimpiadas de Río de Janeiro en 2016, recibió su trofeo con una cinta que decía "100 Jesús", son nítidos ejemplos.

Tal vez los casos más llamativos para los medios de comunicación, en los últimos años, se observan en el continente africano. Las Mama Elephants son mujeres de Costa de Marfil que acompañan a su selección y que, además de apoyar desde las gradas de los estadios, oran con los futbolistas antes de los partidos (Ruiz de la Torre 2014: 31-32). A ello se unen situaciones como la que se produjo a finales de 2016, cuando en Ruanda la federación de fútbol del país sancionó al jugador Moussa Camara, y prohibió a entrenadores y deportistas, el uso de "brujería", que había sido la acusación a ese deportista ruandés ${ }^{4}$.

Estas situaciones se prolongan en otro tipo de acciones que muestran la similitud entre práctica deportiva y religiosa. Las peregrinaciones de los hinchas o aficionados cuando se dirigen al estadio coinciden con la idea de que este último es un templo (Osúa 2009: 329). Seguramente el caso más conocido en España es el del estadio del Athletic de Bilbao, llamado "La Catedral" (Rivero y Cid 2012: 122). Ese "estadio-catedral", donde sus seguidores "forman parte de una etnia especial" (Vázquez Montalbán 2005: 29), se llama San Mamés, "Santo y seña de identidad transformando el campo en un altar" (Villoro 2014: 224) y puede equipararse al nuevo estadio del R.C.D. Espanyol que ha abierto en sus instalaciones de Cornellà-El Prat un espacio para colocar urnas con las cenizas de los socios que así lo deseen, en clara analogía con lo que ocurre en recintos religiosos hasta hoy en día (Osúa 2009: 330).

Tampoco debe asombrar que en las celebraciones de victorias o títulos de los equipos sus aficionados se lancen a las calles como ocurre con las procesiones, pero en este caso los jugadores sustituyen a las imágenes de cualquiera de las religiones que normalmente se muestran una vez al año, tal como sucede con estas celebraciones deportivas. Así, el fútbol espectáculo, como hecho social total si se permite la traslación, se vive igualmente fuera de los espacios propios del desarrollo del juego, en bares, pantallas gigantes o en la casa. Formas de participación social informal y espontánea que remiten al distinto uso social del deporte y de los "comportamientos colectivos" (Madrigal 2009). Si el campo es el templo, el televisor puede ser la "capilla": "La tribuna virtual se sobrepone a cualquier distancia del campo y los televidentes asumen su rol "activo" con la tribuna casera o del bar. La dinámica de gritos genera imaginarios y formas de integrarse al juego" (Meneses 2008: 127). Esas mismas reflexiones es posible reconducirlas hacia otros espacios de ritualidad, en este caso un templo religioso, como el de Tacuba en la Ciudad de México.

\footnotetext{
${ }^{4}$ Infobae. 2016. "Ruanda prohibió la brujería en el fútbol y este gol explica el porqué". Infobae (28 dic.). Disponible en: <http://www.infobae.com/america/deportes/2016/12/28/gol-multas-brujeriahechizo-futbol-ruanda/>. Fecha de consulta: 1 ene. 2017.
} 


\section{EL SANTO NIÑO DE ATOCHA O EL NIÑO FUTBOLISTA}

Lo mismo define al aficionado mexicano. Su fe en el equipo no proviene de la realidad sino de la zona de las promesas incumplidas. La victoria es para nosotros un milagro (Villoro 2014: 15).

Esta imagen religiosa llegó a América, como tantas otras, procedente de la península ibérica. Inicialmente culto mariano a Nuestra Señora de Atocha, derivó en la adoración del niño que la acompañaba. En la primera mitad del siglo XVI el Emperador Carlos $\mathrm{V}$ construyó un templo para tal advocación atendida por los dominicos en Madrid, hoy convertido en basílica. Su presencia se extendió más allá de las fronteras ibéricas llegando a distintos países de Latinoamérica, y en el caso mexicano seguramente el templo más conocido es el ubicado en Plateros, antiguo asentamiento minero en Fresnillo (Zacatecas), aunque también existen iglesias en las capitales de Aguascalientes y Chiapas. En la primera se concretan hoy en día manifestaciones devotas tradicionales con la internacionalización del culto a través del turismo y su comercialización (Fernández 2010: 376), aunque permanecen prácticas como la de los exvotos en forma de agradecimiento y petición (Fernández 2003: 14), o señalando las desgracias del camino recorrido o segregaciones que viven en el vecino país del norte por su condición de migrantes (Martínez y Piña 2013: 47). De hecho el vestir al Niño Dios de emigrante se ha hecho popular, también, en las tiendas dedicadas a tal labor en la Ciudad de México (Vendedor 1, entrevista personal, 1 feb. 2017).

Al igual que otros santos y vírgenes, tanto en España como en América Latina, el santo Niño de Atocha ha sido en algunas de sus ubicaciones físicas un santo en movimiento, que se desplaza a domicilios o localidades cercanas, como el de Plateros que viste de peregrino. De la misma manera, su carácter de niño lo enmarca en las devociones del Niño Jesús, que en México tiene un nítido ciclo festivo entre la noche de Navidad y el día de La Candelaria, el 2 de febrero. El origen de tal fiesta es la liturgia de la purificación y la presentación de los niños al templo. En el libro del Levítico, y según se suponía que la ley funcionaba en tiempos de Jesús, se señala que las mujeres deben llegar al templo a purificarse tras cuarenta días de su parto; tiempo que se prolongaba si la exhibida era niña.

En las casas que cuentan con una figura sacra del Niño Dios, y durante la noche del 24 de diciembre, se efectúa el nacimiento de la imagen acostándola en el pesebre particular, acompañado de los rezos familiares; actividad que se verifica antes de la cena navideña. El Niño permanecerá en esa ubicación hasta el día de La Candelaria, celebración generalizada en México en la que se acostumbra a comer tamales, pagados por quienes sacaron el muñeco del Niño en la rosca de pan dulce que se come el día de la Adoración de los Reyes. Además de ello las familias creyentes, y que llevaron a cabo su nacimiento, retornarán la imagen a su altar habitual siempre con un nuevo vestuario, pagado normalmente gracias a los compromisos adquiridos a través de mandas de familiares o amigos. En esta práctica se produce la diversificación del vestuario, coincidente con las solicitudes de la familia o de la persona que costea la ropa. La variedad de estas advocaciones sitas en casas particulares muestra múltiples formas de celebración, tantas como diferentes tipos de ropajes son utilizados para vestir la imagen. Un ejemplo de esta festividad es el llamado Niñopa ubicado en Xochimilco, en la Ciudad de México, y que se encuentra en posesión de una familia. Sus celebraciones implican la circulación de la imagen en las casas que lo 
solicitan, cumpliendo un círculo ritual de la mayordomía y padrinazgo religioso muy común en relación con las imágenes católicas, al menos en las regiones con presencia histórica o actual de población indígena.

La imagen a la que se refiere este texto se encuentra en Tacuba, parte de la actual Delegación Miguel Hidalgo de la Ciudad de México. En el periodo prehispánico Tacuba era conocida como Tlacopan; además de formar parte de la famosa triple alianza México-Tenochtitlan-Tetzcoco que gobernó durante el siglo XV el Valle de México hasta la llegada de los castellanos. Estos últimos respetaron Tlacopan al establecer alianza con sus pobladores. Al parecer, la primera orden que tuvo presencia en ese territorio fue la de los franciscanos, que también podrían haber iniciado la construcción de lo que con posterioridad sería el actual templo de San Gabriel Arcángel (Serrano y Pérez-Rocha 1998: 45-50), mismo que tuvo diversas modificaciones en los siglos XVIII y XIX y que fue un centro religioso que controlaba un amplio territorio de lo que hoy es la capital del país (Ibid.).

La representación religiosa del Santo Niño Futbolista, venerada junto a otras que están en los altares de la iglesia, se encuentra colocada próxima al altar principal. La fecha del inicio de este culto deportivo no es coincidente según las fuentes utilizadas, ya que para uno de los actuales párrocos, Rafael Fuentes (1 oct. 2016), la idea de vestir la imagen con la indumentaria de seleccionado mexicano se produjo con el Mundial de 1970, llevado a cabo en México. Fue «en esa ocasión cuando creció la devoción de ponerlo de futbolista, y antes lo vestían con los atuendos, le ponían el uniforme del equipo que fuera el campeón, el Nacional" (Ibid.). Otra fuente indica una fecha divergente, puesto que según entrevista al sacristán de la parroquia en 2006, Pablo Sánchez, "la tradición de vestir la imagen con el uniforme comenzó en 1994 con la idea de una feligresa y recibió el apoyo del entonces párroco, padre José Reyes, quien "sabía que este gancho podría atraer a misa a los aficionados no tan religiosos, que por su equipo no dudarían en rezar" ". Incluso una vendedora del mercado central de Tacuba señaló otra fecha: «Sí, a él en algún mundial, me parece que fue en el 86, fue cuando lo vistieron por primera vez de futbolista" (Vendedora 1, entrevista personal, 30 sep. 2016).

El diferendo en fechas no es extraño en entrevistas o datos orales, pero llama la atención que uno de los actuales sacerdotes de la parroquia afirme que la idea de vestir al Niño con playeras de los equipos campeones nacionales se produjo antes de 1970 y que el primer problema, ante tal práctica, surgió cuando fueron campeones los "diablos" del Toluca, "porque ni modo de vestirlo de diablo" (Rafael Fuentes, entrevista personal, 1 oct. 2016). Esta aseveración se acerca más a la fecha de 1994 que a la mencionada por él, ya que los campeonatos del Toluca se produjeron antes de 1970 en las temporadas largas 1966-1967 y 1967-1968, mientras que los triunfos en los torneos cortos, después de una importante sequía, se obtuvieron en los veranos de 1998 y 1999. Pero sea cual fuere la fecha, es obvio que el Niño de Atocha es vestido en los Mundiales con playera de la selección mexicana y con el número 12 a la espalda, fenómeno este que ha significado el incremento de feligresía que arriba

\footnotetext{
5 Aciprensa. 2016. "Imagen de Niño Jesús "futbolista" atrae a católicos alejados en México". Aciprensa (16 jun.). Disponible en: <https://www.aciprensa.com/noticias/imagen-de-nino-jesusfutbolista-atrae-a-catolicos-alejados-en-mexico/>. Fecha de consulta: 12 oct. 2016.
} 
al templo en esas fechas, aunque también llegan en otros momentos. Según el entrevistado, "algunos futbolistas" se acercan para "visitarlo y pedirle por su partido, más cuando andan un poco bajos de fe ¿verdad?" (Ibid.).

Cuando juega la selección y es vestido el Niño, la presencia de aficionados con la camiseta "verde" es ratificada por una trabajadora del Templo en Tacuba ${ }^{6}$. Visita hecha esperanza en el año 2012, cuando la selección olímpica mexicana ganó la medalla de oro. Antes que ello ocurriera, el padre Alejandro Vargas aseveró que como el partido se celebraría a las 9 a. m., la misa para rogar por el éxito del seleccionado mexicano se llevaría a cabo a los 8 a. m. .

Mientras que para el caso del Niño de Atocha de Plateros, lugar de peregrinación, es constante observar los exvotos de súplica y agradecimiento, con múltiples modalidades que se han hecho extensivas con el uso de la tecnología, como son los documentos escritos (Guirette Barbosa 2012), en el caso del Niño situado en Tacuba se encuentran de manera constante, y a sus pies y costados, ofrendas relacionadas con su condición de niño al ser básicamente juguetes y dulces. No son exvotos puesto que no se relacionan con ningún tipo de agradecimiento o solicitud, sino que responden más al carácter de ofrenda que se multiplica durante la celebración de La Candelaria y en diciembre, al conmemorarse su nacimiento; también es visible el crecimiento de estos regalos durante el día del Niño, el 30 de abril.

\section{CUANDO VESTIR IMÁGENES RELIGIOSAS ES POLÉMICO}

Cuando el Gato le preguntó qué bicho le había picado, el Luli le contestó enloquecido que se había pasado medio partido pidiéndole a Dios un milagro y que Dios se lo había concedido (Sacheri 2014: 125).

Elaborar el vestido del Niño, que era una tarea relacionada con la familia y los padrinazgos que construyen la festividad de La Candelaria, sobrepasa en la actualidad este ámbito para ampliarse a la lógica del mercado. Los catálogos de compras se extienden en las tiendas o puestos informales dedicados a esa tarea, o incluso aparecen en internet en lugares como "Mercado Libre" ${ }^{8}$. Seguramente la calle Talavera es la más conocida en la capital de México para realizar las compras. Se encuentra en su centro histórico y el propio gobierno de la ciudad le ha dado el reconocimiento de calle del Niño Dios con placas conmemorativas y estatuas'; aspecto secundado con un sinnúmero de negocios donde la mayoría de interesados compran antes de la festividad de La Candelaria. Las adquisiciones se han extendido al extranjero debido a la emigración de mexicanos a los Estados Unidos, mismos que desean seguir con la tradición de La Candelaria en su nuevo lugar de residencia.

\footnotetext{
${ }^{6}$ En: <https://www.youtube.com/watch?v=Rlk9LFhAOwc>, publicado el 5 jun. 2014. Fecha de consulta: 12 dic. 2016.

7 En: <https://www.youtube.com/watch?v=M93J5OniVOo>, publicado el 10 ago. 2012. Fecha de consulta: 12 dic. 2016.

${ }^{8}$ En: <http://listado.mercadolibre.com.mx/ropa/ropa-para-ni\%C3\%B1o-dios >. Fecha de consulta: 17 oct. 2016 .

9 Son seis las estatuas: Virgen María, Santo Niño de la Salud, San Judas Tadeo, Juan Pablo II, Divino Niño Jesús de Colombia y Santo Niño de Atocha.
} 
La visible oferta de vestidos es muy superior a la deseada por la Iglesia católica, así como la que se refiere a los materiales y complementos que acompañan a los ropajes. Estos últimos oscilan entre los que representan a los santos, hasta los asociados con profesiones o ritos de paso, como el de quinceañera y, por supuesto, los de futbolistas. Para la jerarquía católica la solución a este sacrilegio, desde su perspectiva, transita por la supresión en los catálogos de las fotos «de trajes que no hacen verdadero honor a la dignidad de Quien representan ${ }^{10}$.

Las vendedoras que se encuentran cercanas al templo de San Gabriel Arcángel, también dedicadas a vestir Niños Dios, tienen sus propias opiniones y algunas están permeadas por los juicios de la Iglesia católica, lo que no les impide ofrecer ropajes repudiados por la institución eclesiástica. La señora Julia, locataria del Mercado Central de Tacuba, así lo reconoce:

Yo digo que no, porque luego dicen los padres, ¡de santos no!, porque es un niño, no es un hombre, por ejemplo, yo aquí los visto de lo que quieran, la gente que viene me dice lo quiero del niño de esto, del otro, a veces no sé, y les digo pues no sé cómo va a quedar, pero sí me dicen qué lleva, qué color, y esto el otro... (Julia, entrevista personal, 29 sep. 2016).

Con la misma lógica, la entrevistada mostraba las transformaciones en la imaginería para vestir al Niño. Se ha pasado del Niño de las Palomas, el Niño Limosnerito o el Niño Nueve Corazones, a «una infinidad, nada más que ahora los fabricantes han inventado muchísimo, muchos niños que de esto que el otro, que yo creo que no existen" (Julia, entrevista personal, 29 sep. 2016). Y, por cierto, lo que no falta en las vestimentas son las que corresponden a playeras de equipos de fútbol: "pues lo más comercial sería América, Chivas y Pumas, es lo que más comercia, hay Cruz Azul y a la mejor hay otros equipos" (Vendedora 1, entrevista personal, 30 sep. 2016). La ropa viene acompañada del resto de enseres necesarios para que la imagen sea similar a un jugador de fútbol, ya que lleva zapatos tipo tenis (deportivo) y la vendedora también facilita "el baloncito" (Julia, entrevista personal, 29 sep. 2016).

Esta manifestación religiosa causa diversas reacciones si se conoce el trato que cierta feligresía, medios de comunicación y, sobre todo, la jerarquía católica le otorgan al papel encarnado por las imágenes. De ahí que no sorprenda que algún medio de comunicación nacional hable de ese Niño de Atocha como una figura "mayormente idolatrada", relacionada con el culto a un ídolo ${ }^{11}$. Igual reacción es asumida por parte de la jerarquía católica, a veces no con una intervención directa. En el año 2014 la agencia de información Quadratín se hacía eco de lo expuesto por la Iglesia católica en el Estado de México, y pedía a sus feligreses del Valle de Chalco, que durante la festividad de La Candelaria, "no se vista a los Niños Dios de otra manera que no fuera de blanco, ya que siempre son caracterizados con ropas de personajes como el Chapulín Colorado, futbolistas o luchadores", incluso se afirma que solo son un 15\%

\footnotetext{
${ }^{10}$ Alejandra María Sosa Elízaga. 2016. "Vestir al Niño Dios: ¿devoción, disfraz o superstición?". Desde la Fe. Semanario de la Arquidiócesis de México (31 ene.): 2. Disponible en: < http:// www.desdelafe.mx/apps/article/templates/?a=6641>. Fecha de consulta: 15 oct. 2016.

${ }^{11}$ Héctor Cruz. 2010. "El Santo Niño de los Milagros, eternamente fiel al Tri". Mediotiempo (16 jun.). Disponible en: <http://www.mediotiempo.com/futbol/seleccion-mexicana/noticias/2010/06/ 16/el-santo-nino-de-los-milagros-eternamente-fiel-al-tri>. Fecha de consulta: 11 oct. 2016.
} 
de "mujeres que le gusta complacer al esposo o al hijo". En contraposición, un 75\% "de los trajes que le ponen a las imágenes son de algún santo católico". El argumento, al cual se volverá después con mayor extensión, es que "Dios es Dios y no se puede comparar a santos, luchadores o futbolistas" ${ }^{12}$.

Si lo expuesto fue manifestado en 2014, en 2016 la Diócesis de San Juan del Río (Querétaro), volvía a insistir en no "degradar" al Niño Dios. El vicario de la Parroquia de San Juan Bautista, Alonso Montero, afirmó que "la feligresía ha caído en un error al ataviar a las representaciones del Niño Dios con trajes de héroes del fútbol, profesionistas, o incluso de santos". Su explicación fue que como hijo de Dios "no es posible degradar su condición" y su sugerencia es vestirlo con el ropón de bautismo:

al Niño Dios no se le puede vestir de santo, de ángel o de algún futbolista, es más, ni de médico, porque se supone que todos los santos y todos los ángeles le rinden honor, gloria y adoración a Dios; entonces "¿cómo se le puede degradar a Dios a un Santo?", acciones que el vicario Montero consideraba como algo "ilógico e irracional" ${ }^{13}$.

También desde el Sistema Informativo de la Arquidiócesis de México (SIAME), en enero de 2011, y a través de la pluma de Zoila Bustillo que glosaba las palabras del sacerdote José de Jesús Aguilar, se insistía en no confundir una imagen sagrada con un juguete, es más, la belleza de las imágenes no implica que «las imágenes [...] sienten y no es correcto pensar que tienen frío, se ponen tristes o se enojan si no se les cambia de ropita" ${ }^{14}$. Según el mismo sacerdote, por "muy ejemplares que sean para nosotros los santos, no debemos confundirnos y no debemos "disfrazar a Cristo de santo" ", 15 .

El último ejemplo sobre el vestir a la imagen se toma del año 2016, y está publicado por Ediciones 72, editorial que se presenta como católica mexicana. Después de señalar la tradición mexicana, ya expuesta arriba, puntualiza que "toda devoción popular [...] corre el riesgo de desvirtuarse", por lo que enumera lo que debe ser:

1. La figura del Niño no es un muñeco. Representa a Jesús, es decir a Dios hecho Hombre cuando era Niño [...] 2. Hay quien dice que el Niño "se enoja" si no estrena ropa, lo cual es absurdo. La figura es simplemente una imagen, que no ve ni oye ni siente [...]. 3. Dado que la imagen representa a Jesús recién nacido, sólo hay dos maneras adecuadas de vestirlo: una es con ropita propia de bebé, y la otra es destacando alguno de los atributos que le celebra la Iglesia, por ejemplo, como Sagrado Corazón, Señor de la Divina Misericordia, Buen Pastor, Cristo Rey [...]. 4. Quienes visten Niños Dios, están tan organizados que cuentan con "catálogos" que muestran los diversos trajecitos que se le pueden poner. Al respecto, cabe decir lo siguiente: el sentido de vestir al Niño Jesús es justamente eso, vestirlo, no disfrazarlo. ¿Cuál es la diferencia? Se le viste cuando se le pone un

${ }^{12}$ Marcos Santiago. 2014. "Pide Iglesia Católica a feligresía no vestir Niños Dios de personajes". Quadratín (25 ene.). Disponible en: <https://edomex.quadratin.com.mx/Pide-Iglesia-Catolicafeligresia-vestir-Ninos-Dios-de-personajes/>. Fecha de consulta: 3 oct. 2016.

${ }^{13}$ Rossy Martínez. 2016. "Conmina Diócesis a no "degradar" al Niño Dios", 2016. Disponible en: <http:// www.plazadearmas.com.mx/noticias/local/2016/01/31/conmina_diocesis_degradar_nino_ dios_380872_1013.html> (12 oct.). Fecha de consulta: 3 oct. 2016.

${ }_{14}$ Zoila Bustillo. 2011. "Preocupa ignorancia al vestir al Niño Dios". Olumen. La voz de la Arquidiócesis de Oaxaca (2 feb.). Disponible en: <http://siame.mx/apps/info/p/?a=9431\&z=2>. Fecha de consulta: 16 oct. 2016.

15 Ibid. 
traje adecuado a Su dignidad de Hijo de Dios. Se le disfraza cuando se le viste de criatura, es decir, de un ser inferior a Él. [...] hay gente a la que le parece muy simpático ver la imagen del Niño Dios como san Juditas, san Charbel, san Juan Diego, Papa Francisco, Ángel de la Guarda, [...], futbolista, etc., pero no se trata de disfrazarlo para que se vea chistoso, sino de honrarlo, porque representa a Dios. 5. El catálogo también ofrece trajes de "Niño del éxito y la prosperidad" y "Niño de la suerte", con moneditas de oro; "Ángel de la abundancia", con un cuerno lleno de dinero; "Ángel del amor" con un corazón rojo en la mano, etc. Son aberraciones que convierten la imagen en una especie de "amuleto" que supuestamente garantiza aquello que representa (éxito, dinero, suerte, amor). Quien lo viste así cae en una superstición $[. . .]^{16}$.

La extensa cita condensa los ejemplos y fundamenta aquello que no significan las imágenes para la jerarquía católica, aunque tal circunstancia no sea lo que muchos creyentes opinen o lleven a cabo con ellas.

\section{EL PAPEL DE LAS IMÁGENES Y SU REPRESENTACIÓN}

Había personas que no eran jugadores, pero cuya única pasión era el fútbol. Algunos incluso llegaban en estado de santidad, y con esto quiero decir que amaban el fútbol como los santos aman a los pobres o a su prójimo o a la Iglesia (Dimitrijevic 2010: 83).

No es ocioso recordar que fue Max Weber (1984) quien influyó de forma notable a la hora de considerar que la sociedad moderna tendía a la racionalización y secularización, y que ello comportaría un desencantamiento del mundo caracterizado por la pérdida de los valores religiosos sobre los instrumentales, con un claro decrecimiento de los rituales y fiestas relacionadas con esos valores (Llopis 2006: 118; Weber 1994). No cabe duda que la realidad ha desarmado tal planteamiento teórico y lo ha decantado a posiciones tan contrarias como las del reencantamiento del mundo (Maffesoli 2009a). Situación que Danièle Hervieu-Léger (2005: 275) llamó «desinstitucionalización de lo religioso", en vez de secularización.

Lo expresado alude a las representaciones colectivas que tanta influencia han tenido para conocer el funcionamiento de las sociedades según Emile Durkheim (1982). Experiencia que en el decir de filósofos y científicos sociales también es observable en la necesidad de creación de una religión civil en momentos de cambios políticos transcendentes, como los de la Revolución francesa o la Independencia de Estados Unidos. No hace falta recordar a Rousseau para ver lo expuesto por Robert Bellah (2017 [1967]) respecto a la religión civil, y las posibilidades que esa modalidad de participación social brinda para revelar veneraciones populares o rituales y cultos públicos, destinados a dar cohesión a una comunidad (García 2007: 207). Esta exposición es reafirmada por Hervieu-Léger al entender que lo propuesto por Bellah no es una analogía, sino que constituye una "religión" destinada a "proporcionar un conjunto significativo de los valores últimos, susceptibles de servir de base a la moral de una sociedad" (Hervieu-Léger 2005: 69).

Es así como lo dicho por Durkheim (1982: 38) sobre la posibilidad de que las

\footnotetext{
${ }^{16}$ Alejandra María Sosa Elízaga. 2016. “Vestir al Niño Dios: ¿đevoción, disfraz o superstición?”. Desde la Fe. Semanario de la Arquidiócesis de México (31 ene.): 2. Disponible en: <http:// www.desdelafe.mx/apps/article/templates/?a=6641>. Fecha de consulta: 15 oct. 2016
} 
representaciones colectivas trasciendan el ámbito de lo religioso se convierte en pertinente, y más si se piensa en los espectáculos deportivos que congregan a personas en un espacio determinado y con ceremonias establecidas de antemano. Lo anterior no significa que sea la única posibilidad interpretativa del deporte espectáculo, pero muestra vínculos de sociabilidad que se leen por su capacidad de "suscitar entusiasmo cívico y de ejercer una función de integración simbólica" (Llopis 2006: 119). En el caso de la Europa occidental, por ejemplo, se ha pensado que la pérdida de protagonismo de la religión se sustituyó por acciones o rituales profanos donde se observan conductas religiosas, como lo es el espectáculo futbolístico (Osúa 2009: 323; Payero 2009: 108), un ejemplo más del negocio-espectáculo (Lipovetsky 2016: 37). Lo religioso, como es sabido, no está limitado a instituciones vigentes y reconocidas por ese carácter, y en ese sentido se observan otras acciones humanas vinculadas con el mundo secular "pero que tienen un indudable potencial de transcendencia" (García 2007: 205), y es ahí donde se incorporan los espectáculos deportivos en una especie de transfiguración litúrgica civil (Llopis 2006: 116-117).

Las disquisiciones de Agamben (2008: 172-173) sobre el surgimiento de las formas políticas modernas, que vincula a la constitución del culto monoteísta, hacen hincapié en que la himnología es demostración y constitución del poder, alimento de los dioses (2008: 254), aunque en nuestro caso estos dioses, muchas veces así llamados, son los futbolistas, y los himnos son cantados desde las graderías de los estadios. Una teatralidad que ya había sido observada para el deporte por Roland Barthes (2008: 63), incluso haciendo mención de las manifestaciones corales del público como marcadoras del ritmo, del ritual se añadiría, desde la grada.

Según lo anterior, es comprensible que en el mundo de la globalización de las mercancías y los flujos informativos, la circulación de bienes culturales se ha hecho constante y ha agregado a la llamada religiosidad popular (Álvarez, Buxó y Rodríguez 1989; Marzal 2002) aspectos percibidos fácilmente en los movimientos New Age para unir "circuitos que conectan a las culturas tradicionales y populares con redes globales" (Torre 2008: 50). Una especie de "reanclaje" que usa religiones institucionalizadas o creencias de distinto signo para "proporcionar linaje y memoria, símbolos de arraigo emotivo y pertenencia territorial" (2008: 50). Todo ello ha llevado a hablar, como lo hace Danièle Hervieu-Léger (2005: 13), de una "recomposición del creer", de una "metamorfosis" donde instituciones como la Iglesia católica son impotentes para "controlar la vida de los individuos" (2005: 46-47), y la diseminación de prácticas de esos individuos fuera de los espacios usados por los históricos cultos monoteístas (2005: 55), o incluso en dichos espacios, como ocurre con el Niño de Atocha futbolista. En tal sentido, Hervieu-Léger retoma la idea de religión metafórica de Jean Séguy no como "un residuo de la religión del pasado, sino el dispositivo estructurante de lo religioso moderno" para mostrar comportamientos religiosos en otras modalidades de la acción social. Ello se entiende como posibilidad de los desplazamientos de las religiones históricas "hacia zonas profanas convertidas en autónomas y en objeto de nuevas inversiones religiosas" (2005: 112-118).

Si se sigue esa lógica, las instituciones religiosas establecidas e históricas no son las únicas que legitiman los "bienes de salvación" o las "experiencias de trascendencia" sino que de forma paralela o transversal, como mencionan De la Torre y Gutiérrez (2005: 10), existen nuevas ofertas que subjetivizan las creencias por estar relaciona- 
das con el libre consumo de objetos o principios (Hervieu-Léger 1999). Por este motivo "la mediación mercantil opera en relación con la religiosidad en dos direcciones: 1) la mercantilización de lo sagrado, que atraviesa y reconfigura a las religiones establecidas, y 2) la sacralización de las mercancias y del mercado, que configura formas alternativas de experimentar lo religioso al margen de las iglesias" (Torre y Gutiérrez 2005: 10).

Dicho esto, es fácil advertir cómo en la actualidad la imagen del Niño sagrado que se viste para la festividad de La Candelaria, o en concreto la del Niño de Atocha futbolista, tiene múltiples posibilidades de interacción para los creyentes relacionados con tales imágenes y, al mismo tiempo, variadas lecturas interpretativas según el cometido de los actores involucrados. Si la perspectiva se centra en la representación que ostentan las imágenes sagradas, como la estudiada, se observa que la polémica desatada entre la jerarquía católica no es nada novedosa. Desde el periodo colonial es uno de los puntos nodales de los debates en el seno de la institución eclesiástica para tratar con las devociones construidas más allá de su anuencia (Maquívar 2006). Algo que en la última $V$ Conferencia General del Episcopado Latinoamericano y del Caribe, celebrada en Brasil durante el año 2007, volvió a aparecer. En el discurso inaugural del Papa Benedicto XVI (2008: 9) habló de la religiosidad popular de la siguiente forma:

Esta religiosidad se expresa también en la devoción a los santos con sus fiestas patronales, en el amor al Papa y a los demás pastores, en el amor a la Iglesia universal como gran familia de Dios que nunca puede ni debe dejar solos o en la miseria a sus propios hijos. Todo ello forma el gran mosaico de la religiosidad popular que es el precioso tesoro de la Iglesia católica en América Latina, y que ella debe proteger, promover y, en lo que fuera necesario, también purificar.

Higienización coincidente con lo planteado en la Reforma luterana y, por supuesto, también en el Concilio de Trento que definirá lo que la Iglesia católica deseaba de sus miembros respecto a la veneración de las imágenes (Denzinger y Hünermann 1999: 539). La idea de "purificar" el culto a los santos y las festividades que le rodean también está presente en el "Documento Conclusivo" (2008: 81-82) de la reunión, donde se hace hincapié en la nueva evangelización del territorio americano. Ahí aparecen críticas a la manera de llevarse a cabo, "sin nuevos métodos y expresiones", así como el énfasis puesto en "el ritualismo sin el conveniente itinerario formativo". Juicios que se mitigan al destacar que la piedad popular es el uimprescindible punto de partida para conseguir que la fe del pueblo madure y se haga más fecunda" (2008: 150).

El párroco de la iglesia de San Gabriel Arcángel puntualiza a la perfección lo expresado por sus superiores. Después de mencionar que las madres embarazadas tienen mucha devoción por la imagen del Niño de Atocha, y que llegan a "pedirle al niño por el hijo que viene y acostumbran traerle los primeros regalos que pueden darle a su hijo" (Rafael Fuentes, entrevista personal, 1 oct. 2016), insistió en que la mayor afluencia de público se produce en los Mundiales de fútbol, aunque sus aseveraciones procuran controlar la forma de acercarse de los feligreses a la imagen:

Pues más que nada es sentir la presencia de Dios en la vida de uno, en sus alegrías, en sus necesidades, ¿iverdad?, más que nada una imagen es una imagen, pero nosotros siempre les decimos que hay que buscar, sentir a Dios, pues si tú eres futbolista, que Dios 
está contigo y él quiere que tú seas buen jugador, o que te diviertas, que se alegren la vida. Más o menos esas son las ideas que nosotros manejamos, [...] porque Dios no tiene equipo, ¡Dios es equipo de todos!, y seguir encomendando nuestra selección, porque queremos que gane, ¿verdad? [...]. Pero más que nada lo que tratamos es [...] sentir a Dios en tu vida, que Dios te ama, que Dios está contigo, que Dios goza con tus alegrías, con tus emociones [...]. Dios siempre te está llenándote de fuerza, de coraje, para vencer en la vida, para salir adelante, ese es el Dios que tenemos que descubrir, y que le gusta el fútbol (Rafael Fuentes, entrevista personal, 1 oct. 2016).

El sacerdote se convierte en un mediador de su institución religiosa con la feligresía ante la imposibilidad de gobernar sus creencias y acciones. Así se adelanta a la intervención directa que efectúan los creyentes sobre la imagen y la interpretación de sus actos. Su intención, por lo tanto, es avanzarse a la exégesis de los creyentes, aunque ello no signifique controlar los actos llevados a cabo por los visitantes al Niño de Atocha, o tener un ascendente sobre aquellos referentes religiosos que están ubicados fuera del territorio de la iglesia de San Gabriel Arcángel, como son los altares situados en los domicilios particulares. Hay que recordar, en este sentido, lo expresado por las vendedoras cercanas a tal recinto sagrado, y el tipo de ventas que se llevan a cabo en la calle del centro de la Ciudad de México dedicada a vestir a estas imágenes. Así entiende el párroco su proceder:

uno tiene que respetar, la cómo se llama, la idiosincrasia del pueblos, nosotros no somos dueños, [...], si es el sentimiento de la gente pues hay que respetarlo [...], a veces nosotros damos la impresión como dueños, y no, nosotros somos servidores y buscamos este servicio [...], claro, que sea una cosa desviada pues no; hay que estar al pendiente (Rafael Fuentes, entrevista personal, 1 oct. 2016).

Mientras la Iglesia católica, como institución, debe reforzar "los modos de gestión tradicionales de la memoria autorizada" (Hervieu-Léger 2005: 275), y "reaccionar contra esta amenaza a través de la reafirmación teórica y práctica de la centralidad del magisterio romano" (2005: 281); ciertos actores ligados a ella, aunque sea por vinculación histórica y cultural, juegan a la "circulación de los signos religiosos" existentes, y caracterizados por su "subjetivación" metaforizante de los contenidos de las creencias y [...] la separación de las creencias y las prácticas" (2005: 276). En este punto es donde entra con fuerza lo que expuso Freedberg (1992: 29) con respecto a las imágenes que son tratadas como seres humanos puesto que encarnan, en su presencia, lo que significan. Es decir, muchas imágenes católicas veneradas por la población, o a las que se les efectúan solicitudes de diversa naturaleza, pasan "a ser lo que se cree que representa[n]" (1992: 49-50). Tanto en su trato histórico como en el presente, las imágenes sacras se convierten, en ciertas ocasiones, en alegorías que propician el razonamiento analógico propio de los seres humanos (Lisbona Guillén 2012: 82-83). Si esto es así, la eficacia simbólica que se le otorga al Niño de Atocha se encuentra en la propia imagen, fusionándose representación y lo que representa (Freedberg 1992: 448; Lisbona Guillén 2012: 83). Algo que ya había mencionado Panofsky (1972; 1975) en el tercer y último nivel de interpretación de las imágenes, el del significado y los valores simbólicos, aunque en nuestro ejemplo el origen no se encuentra consciente o inconscientemente en el autor de la imagen u obra, sino en la eficacia simbólica que los creyentes le otorgan. Vestir a la imagen, al santo, es humanizarla para espe- 
rar que cumpla la solicitud, en este caso siendo seleccionado nacional, algo similar como ocurre, a la inversa, cuando se castiga a los bultos sacros.

El Niño de Atocha es concebido por los creyentes que participan de su transformación en las justas futbolísticas de manera divergente a la deseada representación pregonada por la Iglesia católica, más bien se convierte en una real encarnación metonímica del jugador número 12. Condensación temporal de la nación, no cabe duda, pero vívida a través de la imaginería religiosa.

\section{CONCLUSIONES}

Este sentimiento de pertenencia es crucial a la hora de entender por qué hay gente que viaja a Plymouth un miércoles por la noche para presenciar en directo un partido insignificante; sin ese sentimiento, el fútbol no tendría sentido como negocio (Hornby 2012: 89).

Cuando ganó la Argentina el bar se convirtió en un quilombo. Cualquiera abrazaba a cualquiera (Sacheri 2014: 137).

En el "Documento Conclusivo" de la V Conferencia General del Episcopado Latinoamericano y del Caribe aparecen nuevas líneas de preocupación y trabajo de la Iglesia católica; incipientes campos pastorales representados, por ejemplo, por el turismo (Benedicto XVI 2008: 274) o el entretenimiento, que "tiene un campo inmenso de realización en los clubes, en los deportes, salas de cine, centros comerciales y otras opciones que a diario llaman la atención y piden ser evangelizadas" (2008: 250). A pesar de esas propuestas, ya se ofreció en párrafos anteriores las dificultades que tiene la jerarquía católica para comprender y permitir la relación de su feligresía con las imágenes.

Un observador de la realidad contemporánea, como lo es Michel Maffesoli (2009b: 154), advierte esa situación al hablar de "la turbulencia de las emociones figurativas", una especie de "confusión de los sentidos", imposible de comprender para instituciones monoteístas como la católica, cuyo deseo es racionalizar, purgar, todo aquello que procedía de otras formas de construir y percibir la realidad. Alguna de ellas relacionadas con las expresiones figurativas, como son las representadas por las imágenes sacras. La acción metonímica, en tal sentido, está presente en el uso de la imagen del Niño de Atocha. A través del santo se percibe la parte por el todo, donde la figura se convierte en toda la afición mexicana aprovechando su mediación religiosa. Y la misma situación, salvando las distancias, se ha planteado para la significación y la capacidad de abstracción que el espectáculo futbolístico provoca. Un narrador como Nick Hornby lo tenía claro al hablar del "fútbol como metáfora" (Hornby 2012: 117); equiparable a lo expresado por el cineasta Pier Paolo Pasolini (2015: 57), quien consideró el fútbol como un "sistema de signos, es decir, un lenguaje".

Es así que en el caso de estudio se condensan figuraciones precedentes y contemporáneas sin ningún tipo de afirmación doctrinal, tal vez porque los nuevos actos masivos religiosos tienen poco de contenido doctrinal, y se ciñen más al origen etimológico de la palabra religión, el religare, 'estar unido a otro'; el "vibrar en compañía” (Maffesoli 2009b: 61). Así, las situaciones religiosas de carácter contemporáneo, o las que reúnen a personas en conciertos masivos, o espectáculos deportivos, por 
citar dos momentos, responden a su idea de "reencantamiento del mundo" (2009b: 118). Si lo afirmado hasta ahora cuenta con cierta lógica, es indudable que la religación se produce, con distinta forma y mecanismos simbólicos, tanto en el campo de fútbol cuando juega la selección mexicana, como mediante el vestir y toda la actividad relacionada con el Santo Niño de Atocha; además de que se unen sin necesitar de una cercanía física, puesto que en ningún momento la imagen se desplaza a un estadio deportivo.

Bromberger (2000: 273-274) señaló que a diferencia de los sistemas religiosos organizados, el fútbol expresado en los partidos y "el fervor que inspiran" no son un conjunto "autónomo y coherente de representaciones, creencias y prácticas", por el contrario habla de "misceláneas", de "interpretaciones sincréticas" de distinta procedencia religiosa. La discusión a tales afirmaciones podría ser múltiple, pero aquí solo interesa mostrar que ni siquiera las acciones establecidas como rituales institucionalizados por la Iglesia católica tienen las certezas que se asumen en los cultos monoteístas, tal como los sujetos sociales lo demuestran con sus acciones. El resultado innegable para el caso de la selección mexicana, y lo que le entorna, es que el representativo nacional fija sentimientos de pertenencia, lábiles y momentáneos. Una visibilidad, aunque sea por un día, de la mayoría silenciosa, una especie de "patriotismo de noventa minutos" (Alabarces 2010: 86); un nacionalismo desde abajo, si se quiere, que rearticula o reinventa los discursos sobre la nación. Momentos evidentes para Eduardo Galeano (2015: 251) cuando señaló que «el fútbol ocupa un lugar importante en la realidad latinoamericana, a veces el más importante de los lugares, aunque lo ignoren los ideólogos que aman a la humanidad pero desprecian a la gente". Mismo espacio geográfico donde el jugador número doce, y también de manera metonímica, sabe "que es él quien sopla los vientos de fervor que empujan la pelota cuando ella se duerme" (2015: 7).

"Lo único que todavía es capaz de levantar el fervor patriótico es un partido de fútbol", dice Lipovetsky (2016: 298), y ello se hace obvio cuando se conocen estudios como los citados de Villena sobre Costa Rica, donde se reafirma la generación de sentimientos de pertenencia a "una comunidad de fe", incluso de redención nacional, a través de las competiciones deportivas que involucran a la selección del país. Lealtades de esa naturaleza se renuevan merced a "ceremonias rituales" donde el fútbol consigue "en determinadas circunstancias y en ciertos aspectos específicos" ser un complemento "secular de la religión, capaz de otorgar un sentido de pertenencia" (Villena 2010: 145):

En estos casos, el fútbol de representación nacional, como uno de los posibles caminos para reforzar la pertenencia y buscar la trascendencia nacionalista, se articula con la religión y, de esa forma, se sacraliza y se apropia de la magia de la religión, que es también -como lo señaló Benedict Anderson - la magia de todo nacionalismo: convertir el azar en destino [...] (2010: 146).

En México, lo relacionado con la selección mexicana de fútbol tiene un sinnúmero de aspectos para el estudio, por supuesto, sin embargo aquí se desean resaltar dos de ellos que influyen en la manera de vislumbrar, y por ende interpretar, en la opinión pública lo nacional a través del fútbol. El primero remite a los jugadores que no desean, por diferentes motivos, acudir a los llamados del seleccionado en parti- 
dos de competición o de carácter amistoso. Es sabido que tal negativa ocasiona sanciones si son solicitadas a la Comisión disciplinaria de la Federación Internacional de Fútbol Asociación (FIFA), y donde se involucra tanto al club al que pertenece, si este es el que le impide su asistencia, o al propio jugador si es él quien no desea acudir al llamado ${ }^{17}$. Esta explicación, sustentada en la racionalidad de la legalidad internacional en esa materia deportiva, contrasta con la explicación del desaire del jugador como una traición al país, un agravio imposible de resarcir y que merece la imposibilidad de acudir a otro llamado, es decir, la tendencia es una especie de expiación pública gracias a las críticas que recibe por un delito de lesa patria.

El segundo aspecto, y en otro sentido, es la constante polémica en el país sobre la naturalización de jugadores extranjeros en el fútbol nacional. Ya Veremundo Carrillo (2016: 61-62) analizó este debate surgido en los años cuarenta del siglo pasado en la prensa nacional. Si el país contaba entonces, como en la actualidad, con menos del 1\% de población no nacida en su territorio, en el fútbol profesional aparecieron más del 20\% convirtiéndose en un "un extraño bajo sospecha permanente" y al que no "se le reconocen los mismos derechos que al nacido en el país" (2016: 66). Cabe destacar que en los últimos años el número se ha incrementado de manera notable, con la posibilidad de jugar con los equipos, así como incorporarse a la selección mexicana si son requeridos. A pesar de ello, este aumento, junto a la simple oportunidad de ser miembros de la Verde, es un debate y ha condicionado, sin duda, el llamado de alguno de estos naturalizados por parte de los seleccionadores de fútbol en los más recientes cotejos internacionales ${ }^{18}$. La condición de mexicano nada tiene que ver con la legislación vigente, sin embargo reitera, como lo expuso Carrillo para décadas pasadas (2016: 67), la argumentación de los años cuarentas del siglo XX, según la cual el foráneo se convierte en un peligro y posibilita el rebrote de las arengas nacionalistas. Es decir, tal debate se posiciona en esa zona de imprecisión, aunque creativa, de un nacionalismo ajeno a las directrices estatales.

Roger Bartra (2013: 135-136) sitúa la identidad nacional mexicana fuera de un código estructural claro en sus elucubraciones, más bien la ubica como resultado de una especie de "selección cultural" alejada de "instrucciones preestablecidas en un sistema simbólico de mensajes", lo que le hace afirmar que no existe "una sustancia fundamental de la identidad" nacional. Si ello se traslada a la relación entre religiosidad y fútbol, como la expuesta en estas páginas, se crea un debate que, sin estar necesariamente resuelto, posiciona este hecho social espectacularizado en una arena de interrogación:

${ }^{17}$ El Comercio. 2014. "El riesgo que asume un jugador al no acudir a una convocatoria". El comercio (20 ago.). Disponible en: <http://elcomercio.pe/deporte-total/seleccion/riesgos-que-asume-jugador-al-no-aceptar-convocatoria-noticia-1751237>. Fecha de consulta: 7 ene. 2017. Vid. también: El Financiero. 2016. "Vela y 'Gio' dicen no al Tri en Copa América”. El Financiero (17 may.). Disponible en: <http://www.elfinanciero.com.mx/after-office/vela-y-gio-dicen-no-al-tri-en-copaamerica.html>. Fecha de consulta: 7 ene. 2017.

${ }^{18}$ Karla Uzeta. 2016. "Clausura 2016 impondrá nuevo récord de naturalizados". Record (6 ene.). Disponible en: <http://www.record.com.mx/futbol-futbol-nacional-liga-mx/clausura-2016-impondranuevo-record-de-naturalizados>. Fecha de consulta: 7 ene. 2017. Vid. también: Carlos Barrón y Alberto Aceves H. 2016. "Sin límite para los extranjeros en la Liga MX". Adrenalina (24 may.). Disponible en: <http://www.excelsior.com.mx/adrenalina/2016/05/24/1094509>. Fecha de consulta: 7 ene. 2017. 
O bien la religión procede completa y exclusivamente de esta "emoción interior" que es — en realidad - un acto de adhesión a la sociedad [...] y entonces no hay ninguna razón para negarle al espectáculo deportivo la calificación de "religión", [...]; o bien es insuficiente para definir la religión y, si este es el caso, es preciso encontrar otro criterio (HervieuLéger 2005: 100-101).

Lo que resulta evidente es que la actividad futbolística en Estados modernos, como los de América Latina, tiene la cualidad de religación comunitaria que, a lo mejor "no puede llenar por completo una vida" pero "promete placeres" (Sennett 2012: 383) o desesperanzas momentáneas visibles y que, sin duda, exterioriza numerosas formas de expresar la nación.

\section{BIBLIOGRAFÍA CITADA}

Agamben, Giorgio. 2008. El Reino y la Gloria. Por una genealogía teológica de la economía y del gobierno. Valencia: Pre-Textos.

Alabarces, Pablo. 2000. "Los estudios sobre deporte y sociedad: objetos, miradas, agenda", en Pablo Alabarces (comp.), Peligro de Gol. Estudios sobre deporte y sociedad en América Latina: 11-30. Buenos Aires: Consejo Latinoamericano de Ciencias Sociales.

Alabarces, Pablo. 2004. "Entre la banalidad y la crítica: perspectivas de las Ciencias Sociales sobre el deporte en América Latina", en Memoria y civilización. Anuario de Historia, vol. 7: 1-33. Pamplona: Universidad de Navarra. Disponible en: <http://documents.mx/documents/alabarcesentre-la-banalidad-y-la-critica-perspectivas-de-las-ciencias-sociales-sobre-el-deporte-en-americalatina.html>. Fecha de acceso: 13 dic. 2017.

Alabarces, Pablo. 2010. "Entre la banalidad y la crítica: perspectivas de las ciencias sociales sobre el deporte en América Latina", en Samuel Martínez (coord.), Fútbol-Espectáculo, Cultura y Sociedad. Una revisión crítica al negocio mundial: 69-101. México: Afínita Editorial/Universidad Iberoamericana.

Álvarez, Carlos, María Jesús Buxó y Salvador Rodríguez. 1989. La religiosidad popular. Antropología e historia, vol. 1. Barcelona: Anthropos.

Anderson, Benedict. 1993. Comunidades imaginadas. Reflexiones sobre el origen y la difusión del nacionalismo. México: Fondo de Cultura Económica.

Angelotti Pasteur, Gabriel. 2010. "El estudio del fútbol. ¿Un ámbito periférico para la antropología en México?.. Revista de Antropología Experimental 10: 211-222.

Antezana, J. Luis. 2003. "Fútbol: espectáculo e identidad", en Pablo Alabarces (comp.), Futbologías. Fútbol, identidad y violencia en América Latina: 85-98. Buenos Aires: Consejo Latinoamericano de Ciencias Sociales.

Archetti, Eduardo P. 2001. El potrero, la pista y el ring. Las patrias del deporte argentino. Buenos Aires: Fondo de Cultura Económica.

Barthes, Roland. 2008. Del deporte y los hombres. Barcelona: Paidós.

Bartra, Roger. 2013. La sangre y la tinta. Ensayos sobre la condición postmexicana. México: Random House Mondadori.

Bayce, Rafael. 2003. “Cultura, identidades, subjetividades y estereotipos: preguntas generales y apuntes específicos en el caso del fútbol uruguayo", en Pablo Alabarces (comp.), Futbologías. Fútbol, identidad y violencia en América Latina: 163-177. Buenos Aires: Consejo Latinoamericano de Ciencias Sociales.

Bellah, Robert N. 2017 [1967]. "Civil Religion in America". American Studies 2001: Introduction to American Studies. Disponible en: <http://amst2001.neatline-uva.org/items/show/1112>. Fecha de consulta: 12 ene. 2017.

Benedicto XVI. 2008. "Discurso inaugural de su Santidad Benedicto XVI", en V Conferencia General del Episcopado Latinoamericano y del Caribe: 7-24. Bogotá: Consejo Episcopal Latinoamericano. 
Brading, David. 2002. La Virgen de Guadalupe. Imagen y tradición. México: Taurus.

Brohm, Jean-Marie. 1982. Sociología política del deporte. Madrid: Fondo de Cultura Económica.

Bromberger, Christian. 2000. "El fútbol como visión del mundo y como ritual", en Maria Angels Roqué (ed.), Nueva antropología en las sociedades mediterráneas. Viejas culturas, nuevas visiones: 253274. Barcelona: Icaria.

Carrillo Reveles, Veremundo. 2016. «Fútbol, nacionalismo y xenofobia en México: debates en la prensa sobre los jugadores extranjeros y naturalizados, 1943-1945". Desacatos 51 (mayo-agosto): 50-69.

Castells, Manuel. 2005. La era de la información. Economía, sociedad y cultura. I. La sociedad red. México: Siglo XXI.

Da Matta, Roberto. 1982. Universo do Futebol: Esporte e Sociedade Brasileira. Rio de Janeiro: Pinokotheke.

Denzinger, Heinrich y Meter Hünermann. 1999. El magisterio de la Iglesia. Enchiridion, Simbolorum, Definitionum et Declarationum de Rebus Fidei et Morum. Barcelona: Herder.

Dimitrijevic, Vladimir. 2010. La vida es un balón redondo. Madrid: Editorial Sexto Piso.

"Documento Conclusivo". 2008. En V Conferencia General del Episcopado Latinoamericano y del Caribe: 33-304. Bogotá: Consejo Episcopal Latinoamericano.

Durkheim, Emile. 1982. Las formas elementales de la vida religiosa. El sistema totémico en Australia. Madrid: Akal.

Fábregas Puig, Andrés. 2001. Lo sagrado del rebaño. El fútbol como integrador de identidades. Guadalajara: El Colegio de Jalisco.

Fernández Poncela, Anna María. 2003. «El santo Niño de Atocha: origen, función y actualidad”. Cuicuilco 10 (27): 1-35.

Fernández Poncela, Anna María. 2010. "El santo niño de Atocha: patrimonio y turismo religioso". Pasos 8 (2): 375-387.

Freedberg, David. 1992. El poder de las imágenes. Estudios sobre la historia y la teoría de la respuesta. Madrid: Cátedra.

Galeano, Eduardo. 2015. El fútbol a sol y sombra. México: Siglo XXI.

Gameros, Manuel. 2010. "La otra diplomacia: el fútbol y la política", en Samuel Martínez (coord.), Fútbol-Espectáculo, Cultura y Sociedad. Una revisión crítica al negocio mundial: 225-240. México: Afínita Editorial/Universidad Iberoamericana.

García, José Luis. 2007. "Declinaciones de la Religión en la modernidad". Revista Internacional de Sociología 65(47): 203-211.

Guirette Barbosa, María Cristina. 2012. Las transformaciones de testimonios y/o agradecimientos al santo niño de Atocha en el proceso migratorio de zacatecanos hacia Estados Unidos. Tesis de Maestría en Estudios Culturales. Tijuana: Colegio de la Frontera Norte.

Héau, Catherine y Gilberto Giménez. 2005. "Versiones populares de la identidad nacional en México durante el siglo XX", en Raúl Béjar y Héctor Rosales (coords.), La identidad nacional mexicana como problema político y cultural. Nuevas miradas: 81-110. Cuernavaca: Universidad Nacional Autónoma de México.

Hervieu-Léger, Daniéle. 1999. Le pèlerin et le converti. La religión en mouvement. París: Flammarion.

Hervieu-Léger, Danièle. 2005. La religión, hilo de la memoria. Barcelona: Herder.

Hornby, Nick. 2012. Fiebre en las gradas. Barcelona: Anagrama.

Kuper, Simon. 2014. Fútbol contra el enemigo. Un fascinante viaje alrededor del mundo en busca de los vínculos secretos entre el fútbol, el poder y la cultura. Barcelona: Contraediciones.

Lafaye, Jacques. 2002. Quetzalcóatl y Guadalupe. La formación de la conciencia nacional de México. México: Fondo de Cultura Económica.

Lipovetsky, Gilles. 2016. De la ligereza. Hacia una civilización de lo ligero. Barcelona: Anagrama. Lisbona Guillén, Miguel. 2006. "Mejorar la raza. Cuerpo y deporte en el Chiapas revolucionario (19101940). Relaciones 105: 61-106.

Lisbona Guillén, Miguel. 2012. “Por qué quemar santos? El furor iconoclasta en el Chiapas posrevolucionario", en Miguel Lisbona Guillén y Antonio Higuera Bonfil (coords.), El vigor de las imágenes. Miradas interdisciplinarias: 65-100. México: Universidad Nacional Autónoma de México/ Universidad de Quintana Roo. 
Llopis Goig, Ramón. 2006. "El fútbol como ritual festivo. Un análisis referido a la sociedad española". Anduli. Revista Andaluza de Ciencias Sociales 6:115-132.

Madrigal González, David. 2009. "Fútbol y acción colectiva: la reinvención del espacio urbano". Razón y Palabra 14 (julio-agosto): [s. n.]. Disponible en: <http://www.redalyc.org/articulo.oa>. Fecha de acceso: 13 dic. 2017.

Maffesoli, Michel. 2009a. El reencantamiento del mundo. Una ética de nuestro tiempo. Buenos Aires: Dedalus Editories.

Maffesoli, Michel. 2009b. Iconologías. Nuestras idolatrías postmodernas. Barcelona: Península.

Magazine, Roger y Samuel Martínez. 2009. "El sistema de rivalidades futbolísticas en México. Reflexiones en torno al proyecto "Identidades, prácticas y representaciones de los aficionados al futbol en México: un análisis comparativo multi-regional"”, Razón y Palabra 14 (julio-agosto): [s. n.]. Disponible en: <http://www.redalyc.org/articulo.oa>. Fecha de acceso: 13 dic. 2017.

Maquívar, María del Consuelo. 2006. De lo permitido a la probibido. Iconografía de la Santísima Trinidad en la Nueva España. México: Consejo Nacional para la Cultura y las Artes-Instituto Nacional de Antropología e Historia/Miguel Ángel Porrúa.

Martínez, Samuel. 2010. "Presentación”, en Samuel Martínez (coord.), Fútbol-Espectáculo, Cultura y Sociedad. Una revisión crítica al negocio mundial: 9-26. México: Afínita Editorial/Universidad Iberoamericana.

Martínez Pérez, Pablo y María del Refugio Piña Arellano. 2013. "Migración internacional e imágenes de la violencia en los exvotos donados al Niño de Atocha", en Edelmira Ramírez Leyva y Guadalupe Ríos de la Torre (coords.), Estudios Culturales. Prácticas diversas, enfoques pluralistas: 41-57. México: Universidad Autónoma Metropolitana-Azcapotzalco.

Marzal, Manuel M. 2002. Tierra encantada. Tratado de antropología religiosa en América Latina. Madrid: Trotta/Pontificia Universidad Católica del Perú.

Meneses Cárdenas, Jorge Alberto. 2008. "El futbol nos une: socialización, ritual e identidad en torno al futbol". Culturales 4(8): 101-140.

Monsiváis, Carlos. 1991. Los rituales del caos. México: Ediciones Era.

Osúa, Jordi. 2009. "Fùtbol, descontructivisme i religió". Ars Brevis 15: 322-351.

Panofsky, Erwin. 1972. Estudios sobre Iconología. Madrid: Alianza Editorial.

Panofsky, Erwin. 1975. El significado en las artes visuales. Madrid: Alianza Editorial.

Pasolini, Pier Paolo. 2015. Sobre el deporte. Barcelona: Contraediciones.

Payero López, Lucía. 2009. "La nación se la juega: relaciones entre el nacionalismo y el deporte en España”. Ágora para la Educación Física y el deporte 10: 81-118.

Rivero Grandoso, Javier y Karlos Cid Abasolo. 2012. "El estadio: un icono moderno" [capítulo del artículo: "Nuevas mitologías urbanas", de GILAVE, Grupo de Investigación "La aventura de viajar y sus escrituras"]. Ángulo recto 4(2): 110-128. doi: <https://doi.org10.5209/rev_ANRE.2012.v4.n2.40678>.

Ruiz de la Torre, David. 2014. Fútbol que estás en la tierra. Una vuelta al mundo en 40 bistorias. Sevilla: Punto Rojo Libros.

Sacheri, Eduardo. 2014. La vida que pensamos. Cuentos de fútbol. Madrid: Alfaguara.

Sandoval, Carlos. 2013. Fuera de juego. Fútbol, identidades nacionales y masculinidades en Costa Rica. San José: Universidad de Costa Rica.

Sennett, Richard. 2012. Juntos. Rituales, placeres y política de cooperación. Barcelona: Anagrama.

Serra, Marcello. 2015. "Maradona entre la tierra y el cielo". Cuadernos de Información y Comunicación 20: 13-25.

Serrano Espinosa, Teresa E. y Emma Pérez-Rocha. 1998. "Una visión histórica de la parroquia de San Gabriel Arcángel, Tacuba”. Dimensión Antropológica 13 (mayo-agosto): 45-74. Disponible en: <http://www.dimensionantropologica.inah.gob.mx/?p=1340>. Fecha de acceso: 14 dic. 2017.

Tamburrini, Claudio. 2000. ¿La mano de Dios? Una visión distinta del deporte. Buenos Aires: Ediciones Continente.

Torre, Renée de la. 2006. "La guerra de los símbolos en la interacción entre el guadalupanismo y el patriotismo". Revista Portal 3: 21-34.

Torre, Renée de la. 2008. "La imagen, el cuerpo y las mercancías en los procesos de translocalización religiosa en la era global". Ciências Sociais e Religião 10(10): 49-72. 
Torre, Renée de la. 2014. "Los símbolos y la disputa por la definición de los límites entre fe y política en México", en Aldo Rubén Ameigeiras (comp.), Símbolos, rituales religiosos e identidades: los símbolos religiosos y los procesos de construcción politica de identidades en Latinoamérica: 17-38. Buenos Aires: Consejo Latinoamericano de Ciencias Sociales.

Torre, Renée de la y Cristina Gutiérrez. 2005. "La lógica del mercado y la lógica de la creencia en la creación de mercancías simbólicas". Desacatos 18 (mayo-agosto): 53-70.

Tuñón, Jorge y Elisa Brey. 2010. "El fútbol como vehículo de afirmación de identidades periféricas en España", en Esmeralda Mata, Pablo Burillo y Alberto Dorado (comps.), XI Congreso AEISAD. ¿Cómo hacer del deporte herramienta para el desarrollo?: 160-171. Investigación social y Deporte 10. Toledo: AEISAD/autores. Disponible en: <http://www.munideporte.com/imagenes/ documentacion/ficheros/20101105092457congreso_aeisad.pdf>. Fecha de acceso: 14 dic. 2017.

Vázquez Montalbán, Manuel. 2005. Fútbol. Una religión en busca de un Dios. Barcelona: Editorial Debate.

Vélez, Beatriz. 2010. "¿Ciudadanos o clientes? Fútbol-espectáculo y sociedad en Colombia”, en Samuel Martínez (coord.), Fútbol-Espectáculo, Cultura y Sociedad. Una revisión crítica al negocio mundial: 209-223. México: Afínita Editorial/Universidad Iberoamericana.

Vidal Bueno, Jorge. 2012. D10s es Argentino. Nacionalismo cultural argentino y Maradona. Tesis de Maestría en Historia de América. Santiago: Universidad de Chile.

Villena Fiengo, Sergio. 2003. "El fútbol y las identidades. Prólogo a los estudios latinoamericanos", en Pablo Alabarces (comp.), Futbologias. Fútbol, identidad y violencia en América Latina: 2135. Buenos Aires: Consejo Latinoamericano de Ciencias Sociales.

Villena Fiengo, Sergio. 2010. "Del fútbol y otros demonios. Fútbol, religión y nacionalismo en Costa Rica". Anuario de Estudios Centroamericanos 35-46: 137-147.

Villoro, Juan. 2014. Balón dividido. México: Planeta.

Weber, Max. 1984. Economía y Sociedad. México: Fondo de Cultura Económica.

Weber, Max. 1994. La ciencia como vocación. México: Alianza Editorial/Consejo Estatal para la Cultura y las Artes de Chiapas.

Fecha de recepción: 11 de marzo de 2017

Fecha de aceptación: 24 de julio de 2017 